\title{
E-WORK AND PREVENTION OF NEW OCCUPATIONAL RISKS IN SPAIN
}

\author{
Lourdes Mella Méndez*
}

This study analyzes the new "distance work" in Spain, regulated by the labor reform of 2012, especially in light of the new labor risks that may arise. The duty of the employer to ensure the safety and health of workers continues to apply in its fullness, but the worker obligation of cooperating is reinforced, as they would provide services from the place they choose to work from, usually their home. Among the new occupational risks, associated with the working tool of a technological nature, we point out those of a psychosocial nature such as technostress and techno-addition. To prevent and eliminate these new risks, both parties assume new labor contract obligations, including information and specific training in the field.

INTRODUCTION

I. The EMPloyer As Main ResPonsible IN the PREVENTION OF

OCCUPATIONAL RISKS IN TELEWORK 555

II. WORKERS' STANCE: GREATER FREEDOM TO WORK AND GREATER

RESPONSIBILITY TO FACE NEW LABOR RISKS. 558

III. NEW WAYS OF WORKING AND NEW Risks FOR OCCUPATIONAL HEALTH

AND SAFETY

IV. Strengthening of Traditional Protective Measures against New

RISKS 563

CONCLUSIONS 567

\section{INTRODUCTION}

In Spain, distance work was regulated in the labor reform in 2012, specifically by Law No. 3 of July 6, 2012, on urgent measures to reform the labor market. This reform amended the old Article 13 of the Workers' Statute (WS), formerly called "contract work at home", to host the regulation of a new way to work remotely outside of the traditional workplace.

According to the current Article 13.1 WS, this work "will be considered distance work when the provision of labor activity takes place for the most part in the worker's home or any other place freely chosen by

\footnotetext{
*Professor of Labor Law. University of Santiago de Compostela (Spain). Research fields: Labor Law and Social Security.

This paper is a result of the National Research Project carried out by MINECO (Spain), titled "Legal Analysis of Telework in Spanish and Comparative Law" (DER2013-43615-R), leading by Prof. Lourdes Mella.
} 
the employee alternative to the employer's premises". The Spanish legislator defines this new way of work as characterized by the absence of one of the main features of traditional work: The presence of the worker in the workplace. Certainly no one doubts that this is the key element of traditional work and that this is a culture that is now surpassed by the immense possibilities that distance work offers through new information and communication technologies. In other words, the legislator chooses to intentionally regulate the nature of distance work. Thus, the current regulation serves as a general framework, or minimum, both for traditional home work (only in place until 2012) and for the new telework, carried out with new information and communication technology.

Overall, it is positive that the legislator amended Article $13 \mathrm{WS}$, as it can help with the introduction of these new ways of distance working, which has been underdeveloped in Spain so far. However, the content of the provision is brief and important aspects of this new way of working are not regulated in relation to technology used, the privacy of the teleworker, the power an employer has over the employee in this situation or the issues related to representation of the collective interests of these workers.

A positive outcome of the legislation is that one of the few aspects regulated by the legislator in article $13 \mathrm{WS}$ is related to the necessary protection of the teleworker against new labour risks. According to paragraph fourth of the aforementioned provision, these workers "are entitled to adequate protection with regards to safety and health as well as protection arising from the provisions of Law No. 31 of November 8, 1995, for prevention of labor risks" (hereinafter LPLR). Therefore, it is clear that the manner and place of work do not affect the general obligation of employers to protect their workers. However, there is no clarity on the details required in relation to this.

Thus, it can be useful to follow the provisions of the eighth clause of the European Framework Agreement on Telework (EFAT) of July 16, 2002, which even without solving all problems-provides more detailed regulation, especially as to the general obligations of the parties and access to the workplace when this coincides with the worker's home, something always delicate.

Moreover, the collective agreements and the specific rules of the Autonomous Communities concerned with the promotion of telework often also contain some indication of the need to pay attention to workplace risks. 


\section{The EMPloyer as Main Responsible in the PreVention of OCCUPATIONAL RISKS IN TELEWORK}

The duty of the employer to take steps to ensure workers' health, protection from work related risks, including new ones emanating from distance work, finds its foundation in European legislation. Thus, it is necessary to highlight the well-known Directive 89/391/EEC of June 12, 1989 , on the introduction of measures to encourage improvements in the safety and health of workers at work (Framework Directive). Indeed, although it does not directly refer to such risks, its broad terms allow for us to extrapolate that the employer must take distance work into consideration, because their duty of security refers to "all aspects related to work"

The same provision is reiterated in Spanish Law on prevention of occupational risks (LPLR), which transposes the Directive into Spanish Law, by providing that the employer, in compliance with the duty of protection, "must ensure the safety and health of workers at his service in all aspects related to work" . Furthermore, the concept of "occupational risk" is broadly defined, so it is identified with "the possibility that a worker might suffer a particular harm derived from work",

The framework agreements negotiated by the European social partners have increasingly been concerned about the risks arising from new technologies and, in general those of a psychosocial nature. So, it is arguable that the EFAT 2002 already requires employers to extend protection of workers against all types of risk, because, even without explicit reference to specific ones, it states that "the employer is responsible for the protection of health and the professional safety of the teleworker in accordance with Directive 89/391, as well as the specific directives, national legislation and relevant collective agreements". All these rules are based on the principle of total protection for workers against all types of occupational risks (clause 8). More specifically on the matter is the European Framework Agreement on work-related stress, on October 8, 2004, which, although not expressly referring to technological stress derived from the use of new communication technologies, is in agreement in terms of the business obligation to prevent and, if necessary, to solve the problem of work stress, whatever its cause is.

More recently, the Directive 2010/32/EU of the Council of May 10, 2010, implementing the Framework Agreement on prevention of injuries

\footnotetext{
${ }^{1}$ Art. 5.1 Framework Directive.

${ }^{2}$ Art. 14.2 LPLR.

${ }^{3}$ Art. $4.2^{\mathrm{a}}$ LPLR.
} 
caused by sharp objects in hospitals and the healthcare sector, concluded by HOSPEEM (European Association Entrepreneurs of hospital and healthcare sector) and EPSU (European Federation of Public Services) insists on the necessity of protecting workers against all psychological risks. In Spain, this directive has been transposed by the Order ESS/1451/2013 of 29 July, laying down rules for the prevention of injuries caused by sharp instruments in the health and hospital sector, which also includes, almost on equal terms, the need to assess the risks taking into account all psychosocial factors ${ }^{4}$.

In a similar vein, we can point out the new European Strategy for Health and Safety at Work 2014-2020, which highlights the need to improve the prevention of work-related diseases to address new labor risks. In this sense, although the welfare and advancement generated by the introduction of new technologies at work is recognized, it is noted that the effective prevention of occupational diseases requires anticipating the potential negative effects that those technologies have on workers' health. More specifically, it is noted that the changes in work organization that new information technologies have enabled, open up enormous possibilities for flexible work, which is manifested in a multitude of new ways of working and types of workers.

In another vein, worker health also depends on the respect for the legal time off from work that an employee has. The employer must scrupulously comply with working times and needed to avoid new psychosocial risks posed by excessive use of new technologies and protect the health of the workforce. The relationship between the appropriate legal compliance and the health of workers finds expression in the Spanish Constitution ${ }^{5}$, which requires public authorities to ensure the necessary rest of employees by limiting the working day.

From this perspective, Directive 2003/88/EC of the European Parliament and of the Council of November 4, 2003 is of interest, as it relates to certain aspects of the organization of working time and it establishes "the minimum safety and health requirements for the organization of working time" . In order to ensure the health of workers, including those working outside of the traditional workplace, it is essential to respect the rights under the Directive in relation to the minimum daily, weekly and annual rest periods and, correspondingly, the limitations of time in the maximum working week. Of course, those rights are improved in the Workers' Statute in Spain, so the daily minimum rest period of eleven

\footnotetext{
${ }^{4}$ Art. 5.3.

${ }^{5}$ Art. 40.2 .

${ }^{6}$ Art. 1.
} 
consecutive hours per 24-hour period ${ }^{7}$ is reinforced by an additional hour. So "between the end of one work day and the beginning of the next day there will be at least twelve hours" .

As regards to weekly rest, the Directive requires that, for each sevenday period, the worker is entitled to a minimum uninterrupted rest of 24 hours, to be added to the eleven hours of daily rest referred to in article 3, so a minimum of 35 consecutive hours (unless objective, technical or work organization conditions justify a shorter period of rest, which should be at least 24 hours) is guaranteed ${ }^{9}$. Along this line, the WS guarantees that Spanish workers have a minimum and uninterrupted weekly rest of a day and a half, representing a total of 36 hours (given the improvement of an hour in the minimum daily rest) ${ }^{10}$.

Taking these regulations into account, which establish minimum and interrupted daily and weekly rest periods, it is clear that the worker is entitled to refuse to continue working during evenings and weekends, as such work tasks would invade their mandatory rest time. The European legislator requires that the obliged rest period for a worker is "appropriate" and identifies this feature with periods characterized by regular and continuous duration in its enjoyment. Thus, disconnection from work must consist of regular and "sufficiently long and continuous periods of rest to avoid fatigue due to irregular working patterns, or the workers causing injuries, either to themselves, fellow workers or to others, and resulting in damage to their health in a short or long term" ${ }^{\prime 11}$. In this regard, the annual rest period meets this requirement of a long duration, by being fixed to a minimum interval of four weeks ${ }^{12}$ or thirty calendar days ${ }^{13}$. Of course, the interruption -for example, through continuous messages to the mobile phone-, in order to consult or solve ordinary problems does not seem to be such case.

Along with the mandatory rest periods already mentioned, legislation on working time from the EU also tries to guarantee the safety and health of workers through the establishment of a maximum working week or, rather, of its average duration, as it is anticipated that it does not exceed of 48 hours, including overtime, "for every seven-day period" ${ }^{\prime 14}$. If the employee works

\footnotetext{
${ }^{7}$ Art. 3 Directive.

${ }^{8}$ Art. 34.3 WS.

${ }^{9}$ Art. 5.

${ }^{10}$ Art. 37.1.

${ }^{11}$ Art. 2.9 Directive.

${ }^{12}$ Art. 7.1 Directive.

${ }^{13}$ Art. 38.1 WS.

${ }^{14}$ Art. 6.b) Directive.
} 
for more than this time, excess hours may be compensated for through calculating the equivalent rest period over the next four months ${ }^{15}$. Something similar happens in the Spanish legal system, although a distinction between the maximum duration of the ordinary working week and the extraordinary one is added, reaching the maximum of the first 40 hours in an annual average ${ }^{16}$ and the second in 80 hours a year ${ }^{17}$.

\section{WORKERS' STANCE: GREATER FREEDOM TO WORK AND GREATER RESPONSIBILITY TO FACE NEW LABOR RISKS}

The Workers' Statute refers to the worker as a creditor subject of protection in the prevention of occupational risks ("teleworkers have the right" to protection) ${ }^{18}$. Logically, it determines that, a contrario sensu, the employer is the debtor of protection, responsible for ensuring an employee's health and safety. This is certainly the case when work is provided in the traditional workplace, which is justified in the distribution of basic powers in the employment contract. The employer assumes the powers of leading and controlling work activity, and receives the benefit of the work carried out on their premises with their tools.

However, this does not prevent the worker from responsibility and a certain incidental and secondary obligation in the matter, because they must still be aware in accordance to their abilities of their own safety and the safety of others in the workplace. This is done through strict compliance with the preventive measures adopted by the employer and any others that he can implement, especially in unexpected or emergency situations ${ }^{19}$. Consequently, it can be said that ordinarily the worker holds rights and duties in prevention from harm in the workplace.

This general scheme of distribution of responsibility of the parties in the prevention of occupational risks is repeated in the case of teleworking, although here a peculiarity occurs: The strengthening of the responsibility of the worker. Without a doubt, when the worker has the power of choosing the place where he or she wants to work outside of the company, especially if it is located in their family home, it is clear that their dual position leans toward one end, increasing the responsibility, that is, the duty or obligation in the matter onto the worker. In other words, the obligation of the worker is more and is equated to the employer; The worker becomes a "necessary"

\footnotetext{
${ }^{15}$ Art. 16.b) ibid.

${ }^{16}$ Art. 34.1 WS.

${ }^{17}$ Art. 35WS.

${ }^{18}$ Art. 13.4.

${ }^{19}$ Arts. 5.b) WE and 29.1 LPLR.
} 
partner in the daily management of the many aspects that prevention requires on a day to day basis.

In this sense the EFAT states that the worker, after being informed of the company's prevention policy, has the burden of applying it "correctly"20. A good example of such necessary collaboration takes place when the worker is notified by the company about the need to enter their home to assess the labor risks that may exist in the space dedicated to work. If the notification meets all reasonable requirements (i.e., by writing, with notice and an indication of the subject responsible for paying the visit, who will be qualified technical personnel), it seems that the worker must "collaborate" allowing the entry of that mentioned personnel to the workplace located at his home, even if this involves a certain invasion to his privacy.

In case the worker does not want this collaboration, a "self-check" of occupational risks might take place. In this situation, the worker must perform-as we will see, prior training and instruction-the evaluation of those risks and the checking of the adoption of the appropriate security measures, in accordance with the specific documentation that he has to follow with special care. Without any doubt, this second option guarantees a higher extension of workers' fundamental rights to the privacy of their home $^{21}$ and personal and family privacy, but it is also riskier, as the key stages of risk prevention (evaluation and implementation of protective measures) are left practically in the hands of the individual concerned.

In Spain, the provisions of the Autonomous Communities that are regulating teleworking present a clear preference for the second option: Self-check of the work space by the worker. So it is remarkable that some regional text ${ }^{22}$ states that "employees must complete the self-check questionnaire on prevention of occupational risks for teleworking, provided by the competent safety and health service of public employees of the Administration" of the Autonomous Community ${ }^{23}$.

Whatever the collaboration option chosen is, it is easy to see that any of these requires the teleworker have a higher level of care, commitment and diligence in the degree of compliance with regulations and preventive company policy, especially if there is no continuous interactive communication between the parties or the employer cannot electronically control the adequacy of the distance workplace nor the compliance with the

\footnotetext{
${ }^{20}$ Art. 8, second paragraph.

21 Art. 18 Spanish Constitution.

${ }^{22}$ Article 2.3 Decree 9/2011 of 17 March, on the day of non-contact work is regulated by telework in the Administration of the Community of Castile and Leon.

${ }^{23}$ Article 10.5 of the same Decree above cited.
} 
preventive measures provided. In this sense, a collective agreement reflecting the special commitment assumed by the worker in health and safety by providing that they "undertake to comply with and enforce" (in respect to people who inhabit the home) "all safety and hygiene standards that legally or collectively are applicable at any time" and the worker assumes the responsibility of all changes that may be needed in the workplace" from which he provides services, in order for their work space to comply with health and safety requirements ${ }^{24}$.

However, despite the greater involvement of the teleworker, the employer continues to assume his responsibility in prevention, without any cuts or reduction of the protective intensity.

\section{NeW Ways OF Working AND NeW Risks FOR OcCUPATIONAL HEALTH AND SAFETY}

The evaluation of occupational risks in telework and distance work should focus primarily on the specific location where the work activity is going to take place and on the labor instruments used. In addition, there are two other elements that clearly influence the production or the intensity of those risks, such as the system of communication between the company and the teleworker and the character or personality of the worker.

Physical risks are the most easily detectable, and the European legislator refers to them in first place when this issue is addressed in the EFAT 2002, although the current understanding of the labor risks must be broader and more inclusive. These risks can arise from the physical space (room) where work is carried out, and its analysis requires consideration of whether that space is separated from the rest of the house or not. Also of importance is the equipment used to perform the labor activity. If this is understood in a broad sense: Table, chair and technological work tool (computer, smart phone and so on). In Spain, in this area it is important to take into account the Royal Decree 488/1997 of 14 April, on minimum safety and health requirements for work with equipment including data display screens. That rule applies to workers who usually and as a significant part of their working time, use a computer with a data display screen $^{25}$. Without any reference to the place of services, there is no doubt that this rule applies to face to face and remote workers.

While the Annex to that legal text is aware of the physical risks derived

\footnotetext{
${ }^{24}$ Article 38 III Collective Agreement "Orange Espagne, SAU” (Resolution Employment General Direction of August 5, 2014, BOE of 21 August).

${ }^{25}$ Art. 2.b).
} 
from the workplace and, in order to avoid them, establishes objective requirements to prepare the so-called "working environment", the items below should be characterized, at least for the following aspects:

(1) A sufficient space to allow changes in posture and ordinary movements of the worker, thereby it aims to eliminate the risk of musculoskeletal disorders related to incorrect body postures maintained for a long time during working in a space that is too small.

(2) Adequate lighting, both general and special (work lamp), which ensures an appropriate level of clarity and brightness between the screen and the rest of the premises, in order to avoid the risk of serious eye problems.

(3) A particular location of the position so that the light sources do not cause glare on computer screens. In addition to this, other important aspects must be taken into account, such as those relating to proper ventilation, temperature, electrical installation, location of the various elements or (internal and external) noise pollution; All these aspects facilitate the proper development of the work activity and avoid the risk of suffering common diseases, such as headaches, colds or even accidents.

Another aspect of interest can also be the isolated nature of the working space, as a certain intimacy or privacy of it not only seems necessary to facilitate concentration and worker performance, but also to prevent indiscriminate access of outsiders, who could increase the likelihood of becoming an occupational risk.

Regarding work equipment, it is clear that, of the three constituent elements (table, chair and computer equipment), the most dangerous is the computer apparatus with which work is carried out, for the potential of both physical and psychological risks. With regards to the physical risks, these are related to the negative impact that this device can cause to different body parts (such as eyes, back, neck and hands and muscles in general) and can produce problems with vision or limbs. In this regard and in respect of the risks affecting the sense of sight, the above cited Royal Decree refers to the need for a quality data screen, stable and adaptable to the environmental conditions in inclination and orientation. Additionally, this quality can be critical to avoid a new labor risk that, although difficult to assess at the moment, is beginning to cause concern, and this is the possible impact of radiation of electromagnetic waves of technological instruments on workers' health ${ }^{26}$.

Those responsible for safety and health should also take into account the psychosocial risks. These risks arise from the interaction between the

\footnotetext{
${ }^{26}$ J. Popma, The Janus Face of the "New Ways of Work". Rise, Risks and Regulation of Nomadic Work (Working Paper 2013.07. European Trade Union Institute), at 10 (Brussels, 2013).
} 
particular personality of the worker and the conditions in performing their work, and they often reflect the professional competence and emotional relationship of the subject with new technologies, of necessary use in the case of teleworking. Well, two of the most important psychosocial risks are technostress and its opposite techno-addiction ${ }^{27}$.

Regarding the specific case of new technological tools, technostress is generated when the worker receives, subjectively, a mismatch between the required high demands and the scarce personal resources available for the proper use of those at work ${ }^{28}$. The subject suffers from a lack of adaptation to these new tools related to his own training in handling them, his skills and personal tastes and, in general, with the concrete organization of work in the company. This subjective perception of the existence of a mismatch between high external demands (technological, business and organizational) and scarce labor, technical or personal resources for the use of computer technology produces a negative psychological state, of internal suffering, and at the same time an attitude of rejection of that technology. This specific type of stress, with a very specific cause, can lead to a situation of general work stress, of work burnout ${ }^{29}$.

On the other hand, the worker may also fall into the occupational hazard of techno-addition. This addiction is a type of technological stress related with the uncontrollable compulsion to use new technology for long periods of time. In general, these ones tend to be people who are abreast of the latest technological advances and use them to make all possible tasks, including his/her work services, so they end up being dependent on them. Undoubtedly, the continuous labor connection can contribute to the aforementioned dependence, on the pretext of work motivation. As to its nature or identity, technological addiction can have a particular character, as limited as to the use of a single instrument (e.g., mobile) or to the consumption of a particular content or software (i.e., games).

Another similar occupational risk that can arise when the worker works at home or in another similar location, even without new technologies, is the addiction to working alone. Clearly, the fact that the worker transforms his domicile in a workplace or office, which he can access when he wants and starts to perform his work, can itself contribute -along with other personal or labor factors -to the development of a certain degree of work addiction. The

\footnotetext{
${ }^{27} \mathrm{Cf}$. the recent major report Mettling (Transformation numérique et vie de travail) (Sep., 2015), http://www.franceculture.fr/2015-09-16-rapport-mettling-ce-que-le-numerique-change-au travail, at 52.

${ }^{28}$ G. Simmel, Technostress, Knowledge Unit. Fundació Humà, factor in Oct. 2015.

${ }^{29}$ Art. 3 European Framework Agreement on Work-Related Stress (Oct. 8, 2004).
} 
psychosocial damage generated by ongoing work, which does not know any time limits easy to imagine, and therefore any argument about the importance of adequate times of rests and the urgent need to correct or prevent such kinds of compulsive behavior with the category of occupational risk is superfluous.

Finally, technological stress can also be accompanied by secondary effects. In the case of techno stress, the anxiety involves the psychological activation of high levels of stress and inner discomfort due to the use of technological tools, which generates a strong sense of professional and personal incompetence and the refusal to continue interacting with these tools. This leads to technophobia, which is defined by a personal attitude of reluctance to talk or use new technology, as the feeling that it generates in person is fear, hate and belligerence. With regard to fatigue, this appears shaped by strong feelings of mental and cognitive -and even physicallyexhaustion, which prevents an employee from interacting with new technologies and developing their career.

In the case of techno-addiction, fatigue occurs after hours of continuous connection to an electronic device, contrary to what happens with anxiety, which can occur after a time of disconnection with a device even when not significant. This form of anxiety is called FOMO (fear of missing out), that is, fear or concern for missing something or the anxiety for not missing anything ${ }^{30}$.

There is no doubt that these mental risks have the ability to seriously damage the physical and mental health, as well as the work and personal life of the worker, as all or some of them, can appear intermixed together.

\section{Strengthening of Traditional Protective Measures against NeW RISKS}

In order to avoid these important physical and psychosocial risks, that an experience of telework can put one at risk of, the employer should develop a plan of prevention of occupational hazards, where the preventive action is integrated into its overall management system, and in which the telework has a responsibility in relation to the evaluation of occupational risks and the adoption of appropriate protective measures. As already indicated, when it comes to the evaluation and even further practical application of protective measures, the worker concerned will play a more prominent role in telework than in an ordinary case of work in a business center. This does not reduce the duty of the employer, who maintains basic

\footnotetext{
${ }^{30} \mathrm{Cfr}$. Mettling report, op. cit., at 35.
} 
obligations such as, for example, the need to inform and train the worker about the peculiarities of the new way of working remotely, the obligation to make to the employee concerned the specific measures of protection available, to update and modify, if necessary, and a prevention plan.

Two of the first measures for worker protection, which often go together, consist of providing information and training to the employee for them to deliver services in a safer way, especially when the employee works outside of the traditional workplace. According to the EFAT, the employer must inform employees on the "company policy about health and safety at work, in particular about the requirements for display screens" 31 .

However, both the EFAT and the Spanish rules of prevention ${ }^{32}$ suggest that the information given to the worker in this area should be as comprehensive and complete as possible; It is assumed that the more informed and more protected a worker is, the more safety is increased. Therefore, the information should cover general aspects, such as: 1) The prevention plan of the company (for special key issues such as a negotiating committee, reviews). 2) The individual bodies or the groups responsible for the management of the plan. 3) The protection of the workers interests (health and safety representatives, health and safety committee or specific commissions that can be created). 4) The physical and psychological potential risks ${ }^{33}$ both of working outside the workplace (chosen by the teleworker) and at the place in the company, because we cannot forget that both are shared by the subject (partial telework). And, finally, 5) the protection assessments adopted by the employer and made available to workers, including the emergency ones and the control for health of those workers.

The worker must also receive thorough specific training in preventive matters ${ }^{34}$. Undoubtedly, information and training are two key aspects of preventive policy that go hand in hand, reinforcing each other, as they are complementary and interrelated facets. In fact, it must be taken into account that training has to be theoretical and practical. Training is always more demanding, because the aim is to train a worker thoroughly so that for preventing and eliminating occupational hazards by himself, which is

\footnotetext{
${ }^{31}$ Art. 8, second paragraph.

${ }^{32}$ Art. 18 LPLR.

${ }^{33}$ Cf., for example, the Agreement on Implementation of Telework in TELYCO of Dec. 162009. Annex II of the XI Collective Agreement TELYCO (Telefónica "Teleinformática and Communications SAU"), UGT (2008-2010), which develops its $24^{\text {th }}$ clause (http://ugttelyco.org/convenio-colectivo/) and Art. 61.7 of the II Collective Agreement "ONO Group (Cableuropa and Tenaria, SA)" (EGD Resolution of June 11,2013, BOE of July 1).

${ }^{34}$ Art. 19 LPLR.
} 
important in the case of teleworking. As it is the case of the information, the training should be as complete and comprehensive as possible, taking into account the many variables in the workplace (i.e., type of chosen place, people living at home, kind of technological device and others). In this regard, it is arguable that, even without explicit reference to the preventive matter, the obligation to train the workers properly, imposed by the EFAT ${ }^{35}$, and to provide "technical equipment" and "the characteristics of this form of work organization", also involves instructing in labor risks that may derive as from the one or the other ${ }^{36}$.

In order to ensure quality, the ideal is that this training is given by experts, such as members of Prevention Service or similar bodies (in the Regional Administration, it is possible point out the Schools of Public Administration). Furthermore, it is also important to update the training, especially when there is a change of position, location or working tool, or simply accidents occur or adverse effects are detected with the health of the subject.

Moreover, in the field of telework, training is also a key issue on the business side, so both the employer and managers or colleagues in the workplace directly related to the teleworker should also receive specific training on the meaning and features of this new way of working. Although not expressly stated, it is clear that such training should also be aimed at highlighting the possible occupational hazards and the protective measures to be taken in each case ${ }^{37}$. Therefore, business training must be specific for each situation of telework and as wide as possible.

Starting with the most general, training should be directed to instruct the company in the planning and management of distance work, in which the new parameters of time and workplace can lead to new management techniques and measurement of the results by objectives. However, when it comes to setting up working model objectives the impact remote work may have on the health of the worker, which will depend on different elements: The real workload carried out by the subject, the productivity required and even the system of communication between the parties of the contract. Certainly, if the employee works by objectives and performs his work at his or he own leisure without a pre-set time, some health problems from overwork can arise, leading to the so-called "labor self-exploitation". In this

\footnotetext{
${ }^{35}$ Art. 10, second paragraph.

${ }^{36} \mathrm{Cfr}$. sixth paragraph, D) collective agreement on conditions for the provision of services in the BBVA bank in regime of teleworking, on July 27, 2011, http://www.ccoo-servicios.es/bbva/ teletrabajobbva/.

${ }^{37}$ Ex Art. 10, second paragraph, EFAT.
} 
sense, the EFAT requires that the workload and performance criteria applied to a teleworker are equivalent to those of comparable workers of the business center ${ }^{38}$.

Certainly, one of the aspects in which that specific training in prevention is needed is in relation to psychosocial risks derived, especially, from the addiction to new technologies. In view of the already exposed range of potential risks that may arise from an excess of both work and the continued use of those technologies for carrying out the work (i.e., technoaddition, overworking, exhaustion or work stress), it is clear that the importance of respect working hours and rest time and the danger resultant from the lack of complete technological disconnection with the company. Sometimes uncontrolled use of the technological devices may be attributable to the worker who freely chooses to be technologically connected with the company.

Against this, on other occasions, it is the employer himself who, directly or indirectly, causes the permanent connection of that worker in order to get a better use of workforce and consequently business benefits. In this sense, the fact that the employer provides to the latter the aforementioned technological tools can generate, by itself, a sense of obligation on the recipient of them, as the worker may misunderstand his obligation to use the equipment. Therefore, it is necessary to reiterate here and now that the employer, as responsible for the safety and health of workers, must take appropriate protective measures to ensure a teleworker is free of psychosocial risks. This will require that the employer respects the working time limits and resting periods of the employee, trying to ensure the necessary disconnection of the worker at the end of their working day in order to protect their physical and mental health.

On the other hand, psychosocial risks may increase in distance work (even part-time) when this is done with technological disconnection of the company and, therefore, in a situation of complete isolation. So, the EFAT established the obligation of the company to avoid a worker's isolation, ensuring the possibility of regular contact with colleagues and access to information from the company ${ }^{39}$. Although the current model of distance work of the $\mathrm{WS}^{40}$ is a part-time one, these risks do not disappear completely, especially with regard to the challenges of addiction or rejection to the new technologies.

\footnotetext{
${ }^{38}$ Art. 9, second paragraph.

39 Article 9, third paragraph.

${ }^{40}$ Article 13.
} 
Finally, another good measure of protection is the one that consists in the selection of the suitable teleworker by a multidisciplinary team made up of experts, for example, from human resources, risks prevention staff or psychologist. These experts can perform appropriate tests of personality and of adjustment to choose the best candidate for teleworking, selecting those subjects that can be better adapted to the situation and excluding those others for which there is strong evidence of the high probability of failure in this objective (e.g., people with a history of problems with concentration and lack of self-organization at work when they do not have direct control of an employer or a support team or addiction problems or technostress).

In any event, even with a doubt, if the desire and justification of workers in the specific case is firm, they can be given a second opportunity to work away from the business premises. The final idea is not to discriminate against anyone and open the possibility of working remotely to the largest possible number of subjects, as long as their work permits it.

\section{CONCLUSIONS}

1. The manner in which teleworking is legally regulated in Spain involves a new way of organizing work within companies, as it implies a new location for the worker, new working tools, a specific communication system between the remote worker, their colleagues and employer. In addition to this, a new way of exercising management and control of workers and, ultimately new forms of performance measurement through objectives. As a new way of organizing work activities and provide services, telework requires a change in mindset of the parties, whose relationship must be based on greater flexibility, reliability and professionalism.

2. The place to provide services from a distance tends to be the worker's home or another place freely chosen by him or her, without a legal preference for the former place. The provision of this place should be included in the specific telework arrangement and, therefore, it should be communicated to the employer for the purposes of assessing its suitability from the point of view of the prevention of occupational risks. As the worker has the responsibility to choose the location of work, any opposition from the employer has to be based on objective reasons.

3. The evaluation of occupational risks in teleworking should focus on two main sources: The specific location of the work activity and the technical equipment used to perform it. However, there are another two elements that also influence the manifestation or intensity of those risks, such as the system of communication between the company and the 
teleworker (complete disconnection or not from workplace during working hours) and character or personality of the latter. These four elements, especially if poorly combined, can produce physical and psychological or psychosomatic risks for workers and even coworkers (those who the worker engages within a team or during the days that he goes to the center work) or individuals connected with the worker in their private life.

4. The employer holds the final responsibility for the safety and health of workers, and must take the appropriate protective measures to ensure distance work is free of physical (i.e., falls or muscle aches) and psychosocial (for example, technostress or techno-addition) risks. In this sense, and in order to avoid the second type of risks, he must be scrupulous, for example, respecting the limits of working time and rest, and trying to ensure the necessary disconnection of the worker at the end of his working day to protect the employee's physical and mental health.

5. With regard to working time, it is left to the teleworker to manage his/her working hours, unless a specific agreement is in place for something different. This means that if online and simultaneous connection between the employee and other workers exists, and the employer intends to ensure the teleworker works during specific hours the employee must expressly agree with this arrangement. The general rule is that the employee is selfdirecting in their work unless otherwise related to them, which can occur when the intensity of work changes, but must be agreed upon between the parties.

6. The specific representatives in the field of occupational risks are safety representatives and safety and health committees. These bodies should pay more attention to the risks of telework. Trade unions should promote new means of union action, aimed at greater inclusion of teleworkers.

7. Collective bargaining and, where appropriate, individual telework arrangements should regulate, in greater detail, the particularities of telework, for example, the aspects relating to the organization of working time and safety and health of workers. The enterprises' collective agreement is the ideal place to agree the most specific and appropriate solutions for each case of teleworking. 